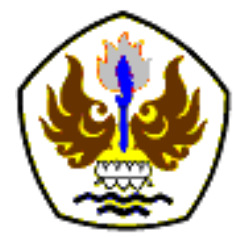

INFOMATEK

Volume 23 Nomor 2 Desember 2021

\title{
MANUFAKTUR BILAH HORIZONTAL AXIS WIND TURBINE (HAWT) TIPE TAPERLESS MENGGUNAKAN AIRFOIL S3024 DENGAN DAYA 500 WATT DI PT. LENTERA BUMI NUSANTARA
}

\author{
M. Dandi Nursidik*, Iwan Nugraha Gusniar, Viktor Naubnome, Oleh \\ Program Studi Teknik Mesin - Fakultas Teknik \\ Universitas Singaperbangsa Karawang
}

\begin{abstract}
Abstrak: Energi angin merupakan salah satu sumber energi alternatif terbarukan yang ramah lingkungan. Seperti di Indonesia angin sangat berpotensial untuk dimanfaatkan, mengingat ketersediaan bahan bakar fosil yang terus semakin menipis. Untuk mengonversi energi angin menjadi energi listrik membutuhkan sebuah teknologi yang bernama turbin angin atau yang sering disebut kincir angin. Turbin angin memiliki tipe ada yang horisontal dan vertikal. Salah satu jenis turbin angin yang memiliki effisiensi $\mathrm{Cp}$ cukup tinggi adalah turbin angin tipe 3 blade propeller yaitu mendekati $45 \%$. Semakin tinggi effisiensi suatu turbin maka semakin bagus dan maksimal juga dalam melakukan pengkonversi energi angin.sehingga ada kemungkinan pengembangan teknologi agar menghasilkan energi listrik yang optimal.Oleh sebab itu pada penelitian ini di lakukanlah manufaktur bilah dengan airfoil S3024 bilah berjenis taperless untuk turbin angin HAWT (Horizontal Axis Wind Turbin). Penelitian ini di lakukan dalam 3 tahap. Tahap yang pertama adalah perancangan, pada tahap ini penulis mengumpulkan data data hasil perancangan seperti data hasil akhir perhitungan, hasil simulasi kemudian melakuan perancangan desain 3D dan 2D. Kedua melakuan pemilihan material yang akan di gunakan untuk turbin angin. Tahap ketuga yaitu melakukan proses manufaktur bilah. Hasil manufaktur bilah taperless dengan airfoil S3024 untuk Turbin angin HAWT (Horizontal Axis Wind Turbin) bahan yang digunakan adalah kayu mahoni kemudian di dapat panjang jari-jari $0.8 \mathrm{~m}$, chord linear dari $0,12 \mathrm{~m}$, sudut puntir $10.27^{0}-5,37^{0}$.
\end{abstract}

Kata kunci: Bilah, Taperless, S3024, Turbin Angin

\section{PENDAHULUAN}

Energi angin merupakan salah satu sumber energi alternatif terbarukan yang ramah lingkungan. Seperti di Indonesia angin sangat berpotensial untuk dimanfaatkan, mengingat kebutuhan energi listrik yang terus meningkat yang berkebalikan dengan ketersediaan

\footnotetext{
*)1710631150096@student.unsika.ac.id

Pertama diterima: 22 Agustus 2021

Direvisi: 27 September 2021

Disetujui untuk publikasi: 1 Oktober 2021

DOI: 10.23969/infomatek.v23i2.4405
}

bahan bakar fosil yang terus semakin menipis dan juga efek buruknya terhadap lingkungan. Untuk mengkonversi energi angin menjadi energi listrik membutuhkan sebuah teknologi yang bernama turbin angin atau yang sering disebut kincir angin (Badan Pengkajian dan Penerapan Teknologi, 2018 [1]).

Turbin angin merupakan alat konversi dari kinetik angin menjadi energi mekanik untuk memutar generator lalu diubah menjadi energi 
listrik. (Zahra, 2016 [2]). Energi angin merupakan hasil dari setengah kali jenis udara dengan luas penampangan cakupan dari turbin angin dan pangkat tiga dari kecepatan anginnya. Diartikan bahwa sedikit saja perbedaan kecepatan angin maka perbedaan energi yang dihasilkan berkali lipat besarnya. Sedangkan energi mekanik yang diperoleh oleh sebuah turbin angin nilainya sebesar perkalian dari kecepatan putaran bilah dengan torsi (gaya yang diberikan oleh lengan bilah turbin angin). Turbin angin memiliki tipe ada yang horisontal dan vertikal. Salah satu jenis turbin angin yang memiliki effisiensi $\mathrm{Cp}$ cukup tinggi adalah turbin angin tipe 3 blade propeller yaitu mendekati $45 \%$. Semakin tinggi effisiensi suatu turbin maka semakin bagus dan maksimal juga dalam melakukan pengkonversi energi angin [2].

Model blade atau bilah suatu turbin angin memiliki tiga jenis yaitu taper, taperless dan inverse taper (Tim Lentera Angin Nusantara, 2014 [3]). Jenis-jenis ini memiliki bentuk desain yang berbeda dan juga sesuai dengan kecepatan angin. Dalam perancangan suatu bilah ada beberapa aspek yang perlu dipahami yaitu mekanika fluida, aerodinamika dan materialnya. Dalam menganalisis suatu turbin angin ada beberapa variabel yang perlu di perhatikan seperti Tip Speed Rasio (TSR), twist, Angel of attack, Power coefficient (Cp), panjang bilah, Airfoil dan lainnya. Airfoil adalah bentuk desain ujung blade berdasarkan gaya angkat dan dorong blade terhadap aliran fluida yang melewatinya. Agar memperoleh kinerja yang baik suatu turbin angin, perlunya mempertimbangkan pemilihan model airfoil yang akan menghasilkan efisiensi aerodinamika yang baik dan tidak menimbulkan efek venturi yang biasa terjadi di bagian bawah airfoil [3].

Seperti penelitian yang sudah pernah dilakukan sebelumnya oleh Dahlan melakukan simulasi bilah turbin angin untuk jenis airfoil NACA 4412 dan 4415 dengan jenis bilah taper dan taperless. Dari hasil penelitiannya menujukan performa airfoil NACA 4412 untuk jenis bilah taperless lebih baik dari pada untuk jenis bilah taper dan juga airfoil NACA 4415. pada simulasi pengujian Cp-TSR untuk TSR 7, Cp pada taperless bernilai $52 \%$ dan Cp pada taper bernilai 50\% (Dahlan, 2016 [4]). Sedangkan Madi (2016) melakukan studi perancangan Horizontal Axis Wind Turbine jenis bilah taper untuk uji performa airfoil Clark-Y, NACA 4412, NACA 3612, NACA 4418, NACA 0012, dan NACA 0018. Hasil penelitiannya menujukan jenis airfoil terbaik yaitu NACA 4412 dengan efisiensi sebesar $52 \%$ sedangkan jenis airfoil efisiensi terendah adalah Clark-Y sebesar 39\% (Madi, 2016 [5]).

Dalam penelitian ini akan mencoba melakukan manufakturing bilah dengan airfoil S3024 jenis 
taperless untuk turbine angin tipe horizontal yang akan diaplikasikan di TSD 500 Watt di PT. Lentera Bumi Nusantara.

\section{METODOLOGI}

Sebelum memulai penelitian kita perlu menentukan material yang akan di gunakan dalam pembuatan bilah, mempersiapkan data awal dalam perancangan yang dibutuhkan pada proses manufaktur seperti geomerti bilah taperless S3024. Kemudian data geometri bilah tersebut di masukan ke software Qblade, dengan memasukan angka-angka hasil perhitungan geometri bilah yang telah di buat sebelumnya. Setelah selesai melakukan simulasi dan mendapatkan koordinat bilah yang didapat dari data hasil perhitungan perancangan, selanjutnya yaitu membuat desain 3D dan 2D menggunakan software Solidwork 2015. Selanjutnya dilakukan proses manufaktur bilah taperless S3024 yang di awali dengan proses pemilihan dan mempersiapkan kayu yang akan di gunakan, kemudian membuat mal positif atau negatif sesuai dengan airfoil bilah, mengukur dan menentukan posisi titik ujung airfoil pada bagian ujung bilah, mengukur dan menentukan posisi titik ujung airfoil pada bagian pangkal bilah, membuat garis bantu yang menandakan bagian kayu yang akan dibuang, membuat garis-garis elemen pada kayu, membentuk dan memperhalus bilah menggunakan amplas gerinda dan melakukan pengecekan secara berkala menggunakan mal yang telah dibuat pada bagian-bagian bilah sesuai dengan garis elemen yang telah dibuat, memperhalus kembali permukaan dengan menggunakan amplas, membentuk pangkal dan memberikan lubang pada bilah agar dapat dipasang sesuai pada generator. Kemudian yang terakhir melakukan proses pelapisan pada bilah mengunakan cat atau pernis.

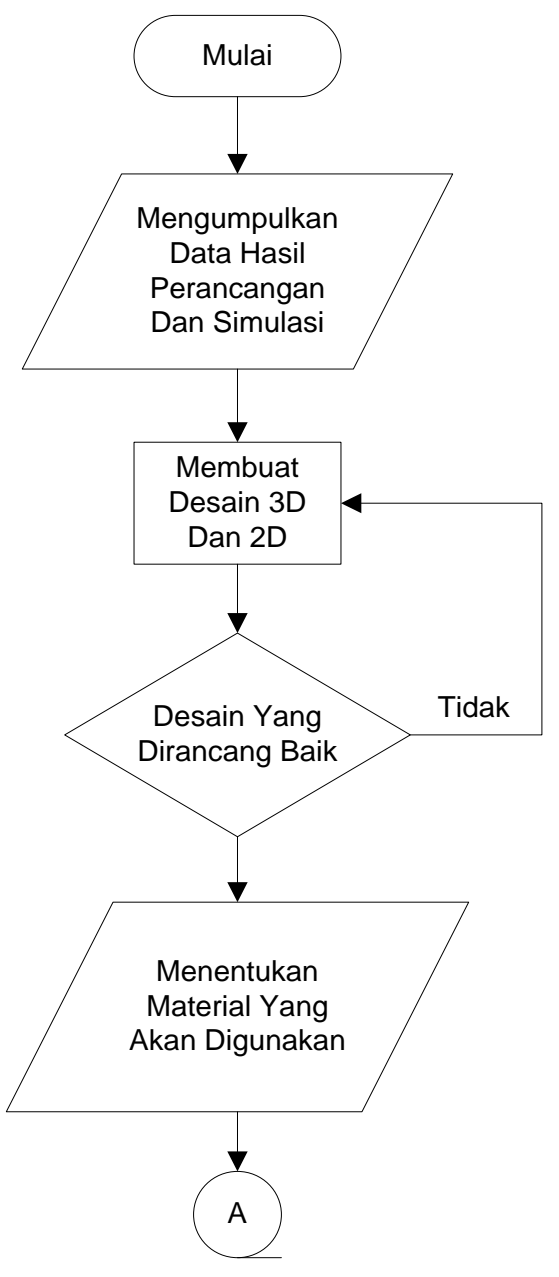



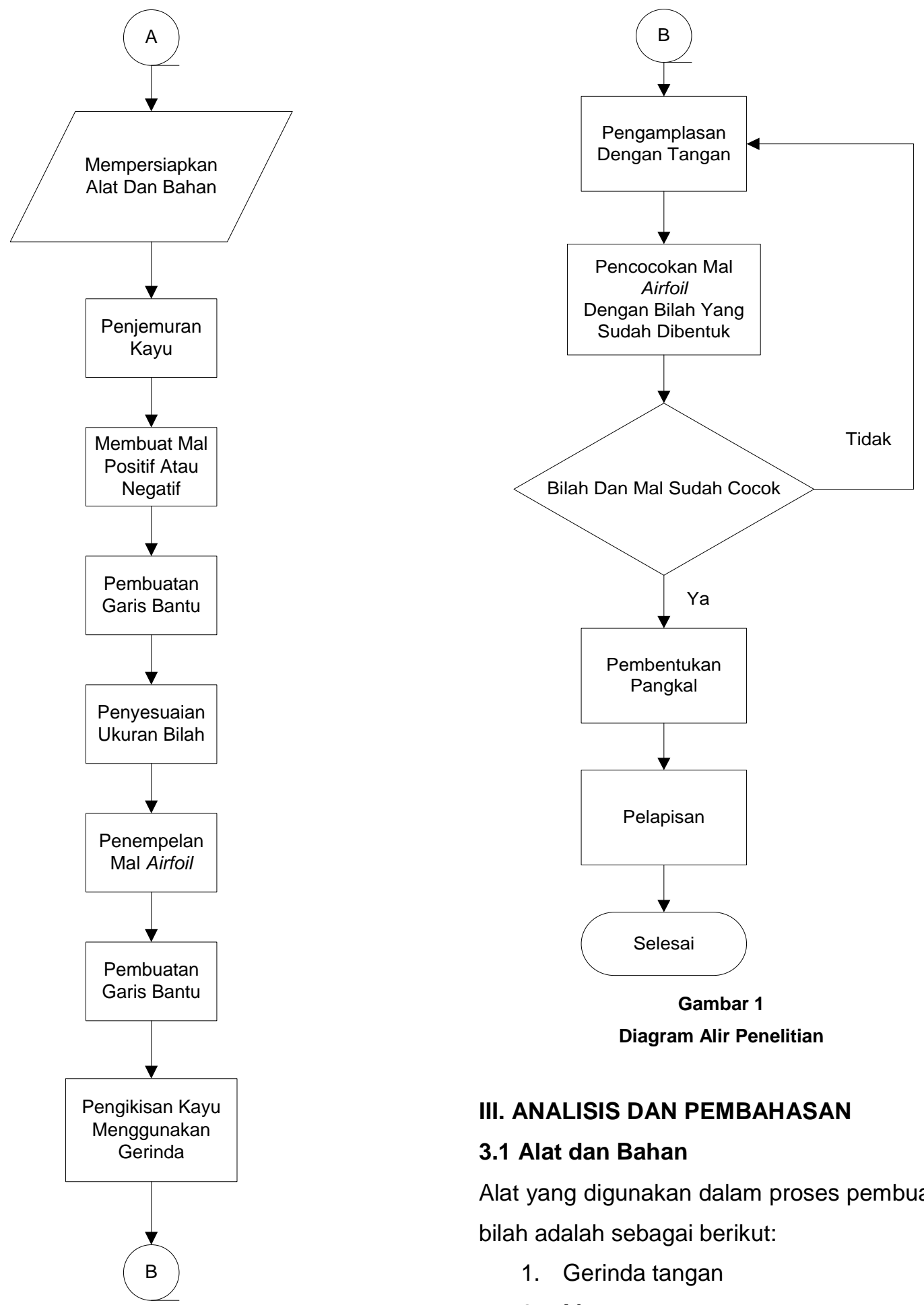

\section{ANALISIS DAN PEMBAHASAN}

\subsection{Alat dan Bahan}

Alat yang digunakan dalam proses pembuatan bilah adalah sebagai berikut:

1. Gerinda tangan

2. Meteran 


\section{Golok/Parang}

4. Gergaji Potong

5. Mesin ketam kayu

6. Mistar

7. Kunci shok

8. Jangka sorong

9. Amplas $80,180,240,1000$

10. Timbangan

11. Mesin bor duduk

Bahan yang digunakan dalam proses pembuatan bilah adalah sebagai berikut:

1. Balok kayu mahoni $120 \mathrm{~cm} \times 15 \mathrm{~cm} \times$ $3 \mathrm{~cm}$

2. Lem kayu

3. Triplek kayu

4. Dempul

\subsection{Pemilihan Bahan}

Terdapat beberapa pilihan material yang dapat digunakan untuk bilah, seperti logam, komposit, styrofoam, dan kayu. Pada bukunya, Piggott memaparkan kelebihan dan kekurangan masing-masing material. Misalnya, penggunaan steel sebagai material bilah menyebabkan bilah menjadi terlalu berat dan sulit berputar, sedangkan alumunium tidak cukup kuat dan cenderung menyebakan kepatahan.Komposit seperti resin polyster merupakan material yang umum digunakan, namun diperlukan cetakan atau master blade untuk membuatnya, dan memakan biaya yang lebih besar. Bahan styrofoam memiliki sifat yang ringan, mudah dibentuk namun mudah patah dan membutuhkan sambungan ke generator (Piggott, 2011 [6]).

Kayu merupakan pilihan yang paling umum digunakan dalam pembuatan bilah turbin angin dikarenakan sifatnya yang ringan, kuat, mudah dibentuk dan getas. Kayu yang digunakan pada pembuatan bilah sebaiknya adalah kayu yang lunak dan ringan, memiliki serat yang rapat dan bebas dari mata kayu jika memungkinkan. Beberapa contoh jenis kayu yang umum digunakan menjadi bahan bilah adalah pinus, jati, dan mahoni. Kayu yang dipilih pada proses manufaktur ini adalah kayu mahoni (Swietenia macrophylla) karena kayu mahoni memiliki tingkat kekerasan dan kelenturan yang baik, namun alasan utama dipilihnyakayu mahoni adalah karena ketersediaan kayu mahoni yang melimpah di wilayah penelitian penulis.

\subsection{Simulasi Desain}

Dalam proses manufakturing bilah, setelah mempersiapan segala perlengkapan, bahan, alat, metode kerja atau langkah pembuatan serta peralatan pendukung linnya. Hal pertama yang perlu disiapkan adalah desain bilah, desain yang disiapkan meliputi desain tiga dimensi pada solidwork yang kemudian direalisasikan dalam bentuk desain dua dimensi dengan skala satu banding satu. Sebelum memasuki tahap desain dilakukan 
simulasi bentuk geometri bilah dengan menggunakan software Qblade, dengan memasukan angka-angka hasil perhitungan geometri bilah yang telah di buat sebelumnya pada kolom yang berwarna abu-abu yang meliputi nilai jari-jari parsial, twist linear dan chord linear, yang di tunjukan pada gambar berikut:

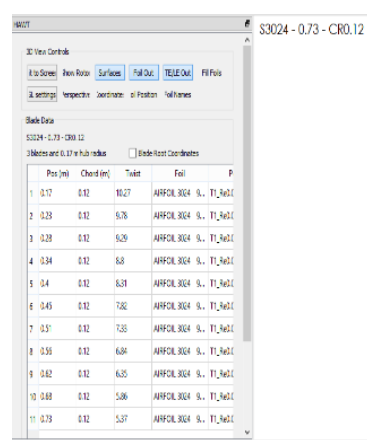

Gambar 2

Simulasi Geometri Bilah Taperless S3024 menggunakan Software Q-blade

Tabel 1

Geometri Bilah

\begin{tabular}{cccc}
\hline Elemen & $\begin{array}{c}\text { Jari-jari } \\
\text { parsial }\end{array}$ & Twist & Chord \\
\hline 0 & 0,17 & 10,27 & 0,12 \\
\hline 1 & 0,23 & 9,78 & 0,12 \\
\hline 2 & 0,29 & 9,29 & 0,12 \\
\hline 3 & 0,35 & 8,80 & 0,12 \\
\hline 4 & 0,41 & 8,31 & 0,12 \\
\hline 5 & 0,47 & 7,82 & 0,12 \\
\hline 6 & 0,53 & 7,33 & 0,12 \\
\hline 7 & 0,59 & 6,84 & 0,12 \\
\hline 8 & 0,65 & 6,35 & 0,12 \\
\hline 9 & 0,71 & 5,86 & 0,12 \\
\hline 10 & 0,8 & 5,37 & 0,12 \\
\hline
\end{tabular}

Sebelum melakukan pendesainan dan manufaktur bilah, terlebih dahulu menentukan parameter yang akan digunakan sebagai dasar perancangan geometri bilah antara lain yaitu:

Daya angin yang dibutuhkan $(\mathrm{Pa})$

$P_{a}=\frac{1}{2} p A v^{3}$

Dimana :

$\mathrm{P}_{a}=$ Daya angin yang dibutuhkan $(\mathrm{W})$

$\rho=$ densitas angin $\left(\mathrm{Kg} / \mathrm{m}^{3}\right)$

$A$ = luas sapuan bilah $\left(\mathrm{m}^{2}\right)$

$v=$ kecepatan angin $(\mathrm{m} / \mathrm{s})$

luas sapuan bilah

$A=\pi r^{2}$

Dimana:

$r=$ jari-jari bilah $(m)$

Tabel 2

Hasil Perhitungan Daya Secara Teori

\begin{tabular}{cc}
\hline $\begin{array}{c}\text { Kecepatan } \\
\text { Angin (m/s) }\end{array}$ & $\begin{array}{c}\text { Daya Angin } \\
\text { S3024 (W) }\end{array}$ \\
\hline 1 & 1,23 \\
\hline 2 & 9,85 \\
\hline 3 & 33,24 \\
\hline 4 & 78,79 \\
\hline 5 & 153,89 \\
\hline 6 & 265,92 \\
\hline 7 & 422,28 \\
\hline 8 & 630,34 \\
\hline 9 & 897,49 \\
\hline 10 & 1231,13 \\
\hline 12 & 1638,63 \\
\hline 13 & 2127,38 \\
\hline
\end{tabular}

Pada kali ini bilah yang di desain adalah bilah tipe taperless dengan airfoil S3024, tebal chord 0,12 m dan jari-jari bilah $0.8 \mathrm{~m}$. Setelah mendapatkan koordinat bilah yang didapat dari data hasil perhitungan 
perancangan, selanjutnya yaitu membuat desain 3D dan 2D menggunakan software Solidwork 2015 dan menghasilkan gambar teknik bilah.

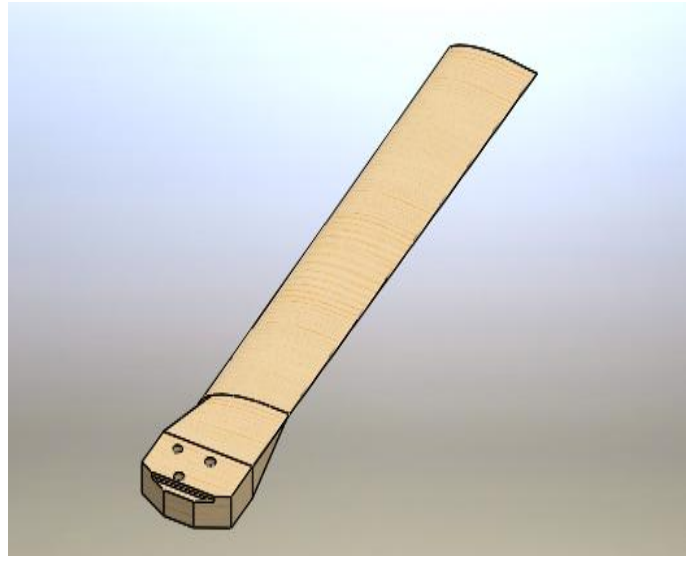

Gambar 3

Desain 3d Bilah menggunakan Software Solidwork

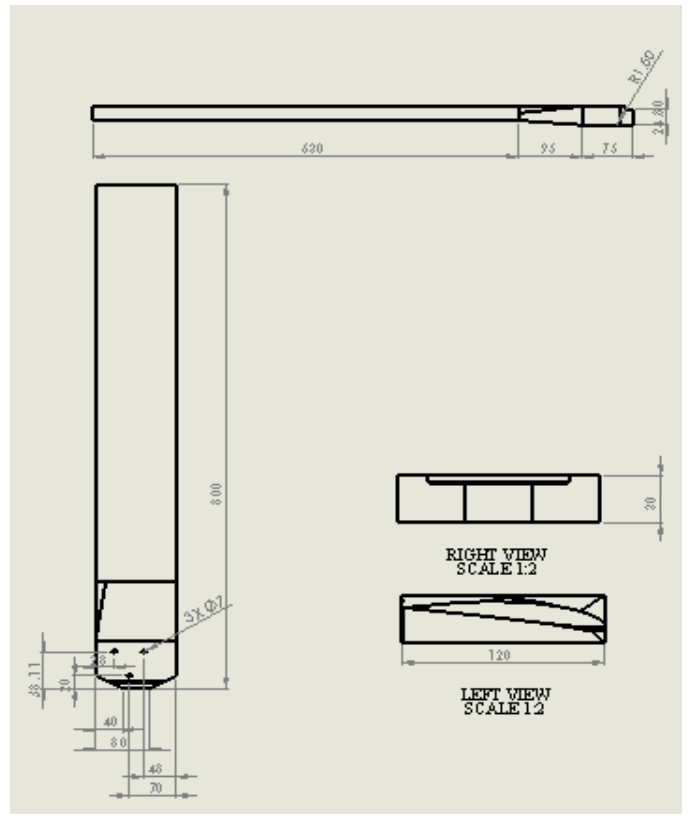

Gambar 4

Desain 2d Bilah menggunakan Software Solidwork

\subsection{Proses Manufakturing}

1. Persiapan material kayu

Ukuran bilah yang akan dibuat berdasarkan perancangan yang telah dilakukan adalah 80 $\mathrm{cm} \times 12 \mathrm{~cm} \times 3 \mathrm{~cm}$, dibutuhkan 3 balok kayu mahoni. Langkah awal dalam proses pembuatan bilah adalah pengeringan dan pemotongan kayu. Pada percobaan yang dilakukan ini tidak dilengkapi fasilitas pengeringan, sehingga dilakukan penjemuran kayu, kayu dikeringkan seadanya dengan cara penjemuran tetapi tidak boleh mengenai matahari langsung karena bisa terjadi keretakan di ujung kayu, tujuan penjemuran adalah untuk mengurangi kadar air pada kayu dan supaya massa kayu tidak terlalu berat dan untuk memudahkan pemotongan dan penggerindaan. Pada percobaan ini, kayu yang dijemur selama 7 hari.

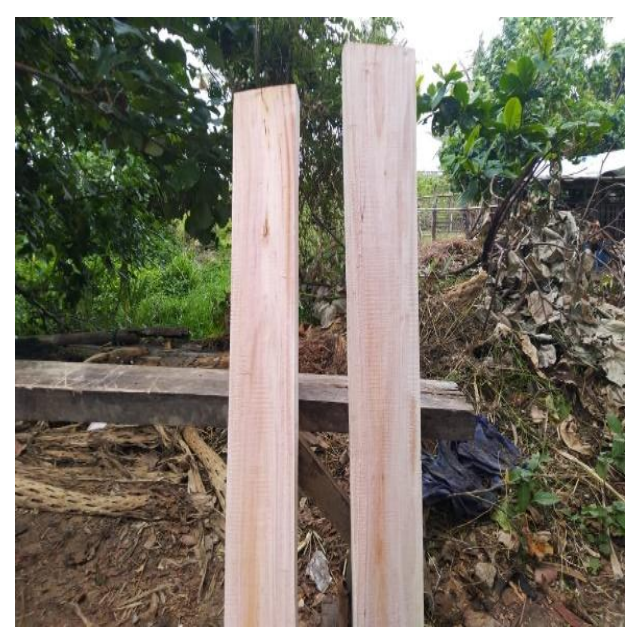

Gambar 5

Proses Penjemuran Kayu 


\section{Pembuatan mal}

Langkah berikutnya adalah pembuatan mal atau cetakan airfoil bilah. Hasil gambar bilah di solidworks yang telah dibuat khususnya penampang bilah atau airfoil dicetak dengan skala 1:1 lalu ditempel pada triplek.

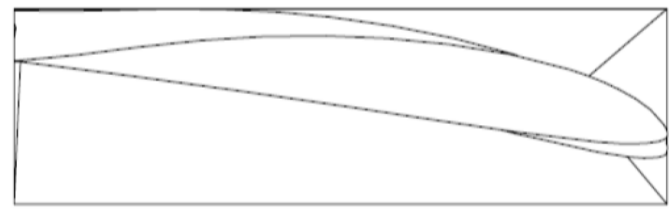

Gambar 6

Bentuk 2d Mal Airfoil per Elemen

Triplek dipotong menjadi 2 bagian lalu dibentuk mengikuti bentuk airfoil hasil cetakan dengan menggunakan gergaji ulir.

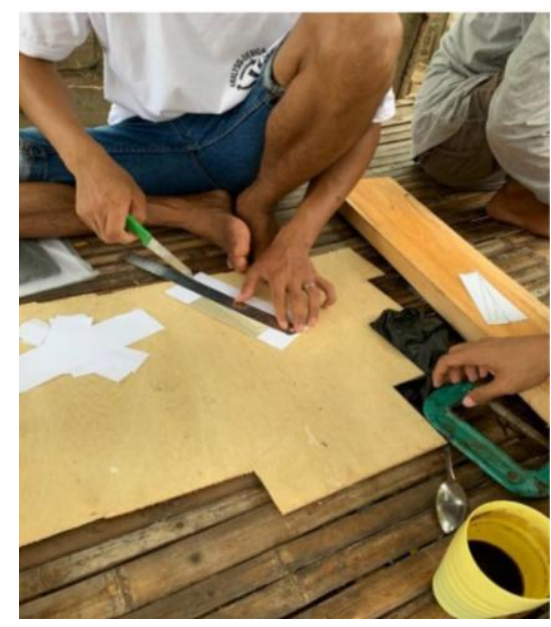

Gambar 7.
Pada perancangan bilah jenis taperless, digunakan $1 \mathrm{mal}$ saja karena bentuk bilah dari ujung sampai pangkal sama.

\section{Pembentukan bilah}

Setelah dilakukannya penjemuran pada kayu tahap selanjutnya adalah proses penggergajian dan pengetaman, proses ini dilakukan untuk menyesusaikan ukuran bilah sesuai dengan perancangan yang sudah ditentukan dan memudahkan proses penggerindaan sesuai bentuk yang dibutuhkan.

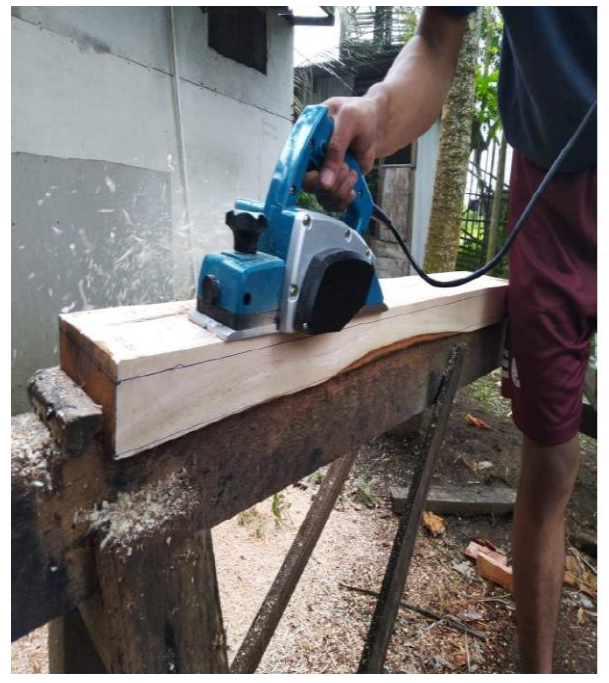

Gambar 8.

Proses penyesuaian kayu manohi dengan mesin ketam
Jika ukuran kayu sudah sesuai kemudian langkah selanjutnya adalah penempelan mal airfoil menggunakan lem pada bagian ujung bilah. Pada mal airfoil dapat terlihat airfoil pada bagian ujung bilah sehingga dapat dibuat titik dan garis bantu pada kayu. Garis bantu yang dibuat bertujuan untuk membantu proses pengikisan agar twist bilah dari ujung hingga pangkal bilah dapat terbentuk dan bentuk 
bilah tetap sesuai airfoil tanpa bilah terkikis terlalu dalam.

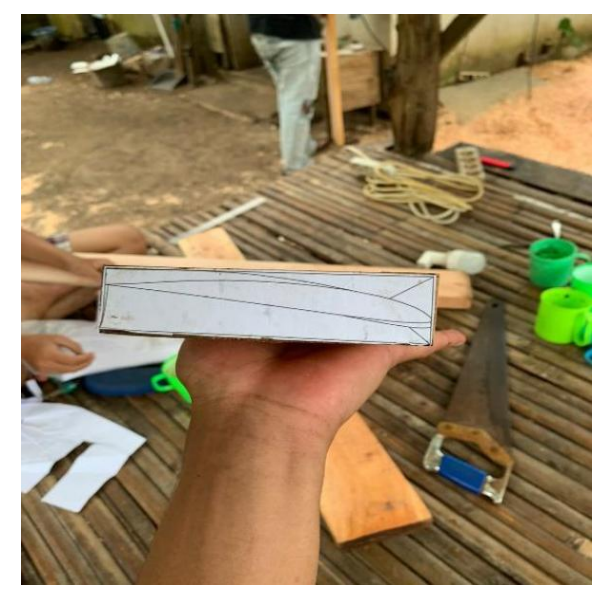

Gambar 9

Penempelan Mal Airfoil pada ujung Bilah

Setelah itu, kayu dikikis mengikuti panduan garis bantu yang telah dibuat menggunakan gerinda amplas dan mengikuti panduan garis bantu yang telah dibuat, bilah dibentuk mengikuti mal airfoil yang telah dibuat.

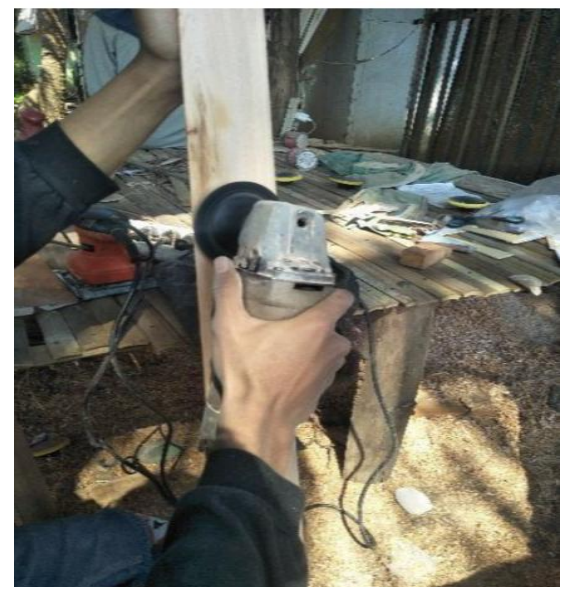

Gambar 10.

Proses Penggerindaan mengikuti Bentuk Mal Airfoil
Penggunaan gerinda amplas dimulai dari amplas dengan nomor yang lebih kecil atau amplas yang lebih kasar, dan menuju amplas dengan nomor yang semakin besar atau semakin halus. Pengikisan dilakukan dengan menggunakan amplas kasar jika area yang ingin dikikis banyak agar proses pengikisan tidak memakan waktu yang lama, sedangkan pengikisan menggunakan amplas yang semakin halus agar area yang terkikis tidak terkikis terlalu dalam. Pada proses pembuatan bilah ini, digunakan amplas dengan nomor 80 , 180, 240 dan untuk gerinda amplas dan 1000 untuk finishing dengan menggunakan amplas tangan.

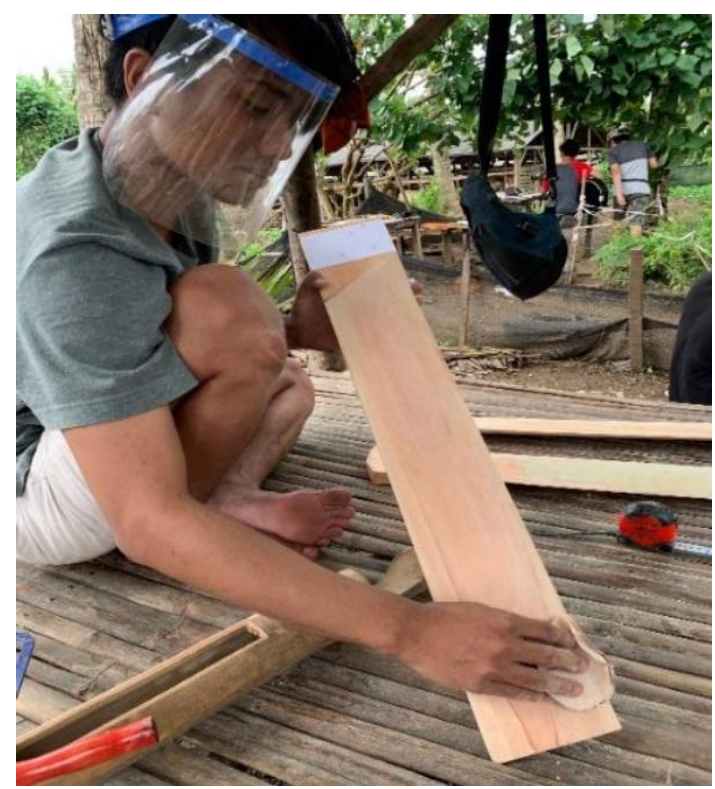

Gambar 11.

Proses Penggampelasan Mengunakan Tangan Sebelum Pengecekan Mengunakan Mal Airfoil 


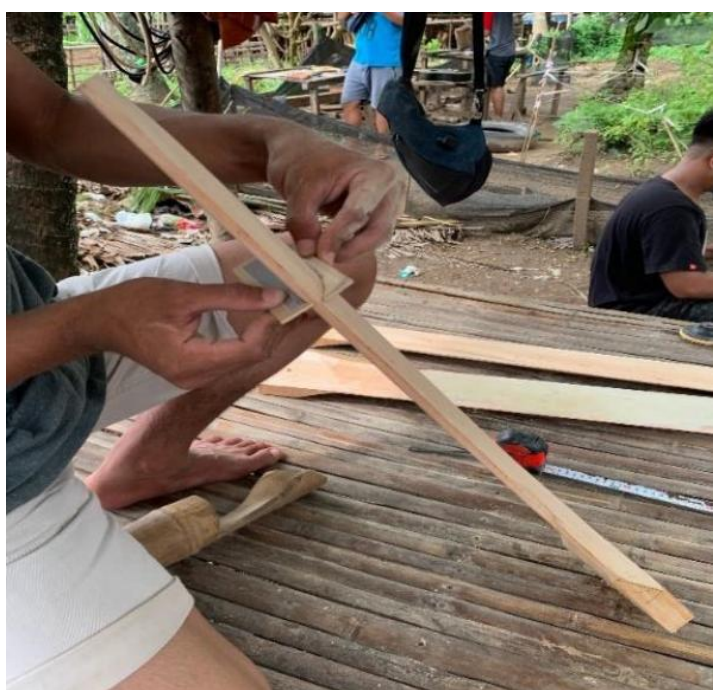

Gambar 12.

Proses Pencocokkan Mal Airfoil dengan Bilah yang Sudah dibentuk

Bilah yang telah selesai dibentuk mengikuti mal airfoil di setiap elemennya, dihaluskan dengan amplas tangan, kemudian dilanjutkan pada tahap pembuatan bentuk pangkal dengan membuat mal $2 d$ terlebih dahulu.

\section{Pembentukan Pangkal}

Setelah bentuk dimensi airfoil bilah telah selesai, langkah berikutnya adalah pembentukkan pangkal bilah. Seperti halnya bagian airfoil, bagian pangkal bilah juga memerlukan mal sebagai patokan ukuran. Mal yang digunakan di print pada kertas dengan skalal 1:1. Sebelum mal di tempel, terlebih dahulu kita tentukan panjang bilah yaitu berjarak $17 \mathrm{~cm}$ dari segmen ke 0 atau pangkal airfoil, untuk mengantisipasi kesalahan dari penjumlahan panjang segmen, maka pengukuran dapat dilakukan dari ujung bilah dengan panjang $80 \mathrm{~cm}-3 \mathrm{~cm}=77 \mathrm{~cm}$.

Setelah titik paling belakang ditentukan, selanjutnya mal yang telah di print dengan sekala 1:1, ditempel dibagian belakang bilah. Hal yang perlu diperhatikan adalah penempelan kertas harus tepat dan suku terhadap panjang bilah, kemiringan pada penempelan mal dapat mengakibatkan bentuk pangkal yang kuarang presisi dan lubang baut yang tidak tepat, sehingga bilah sulit bahkan tidak bisa dipasang di hub generator.
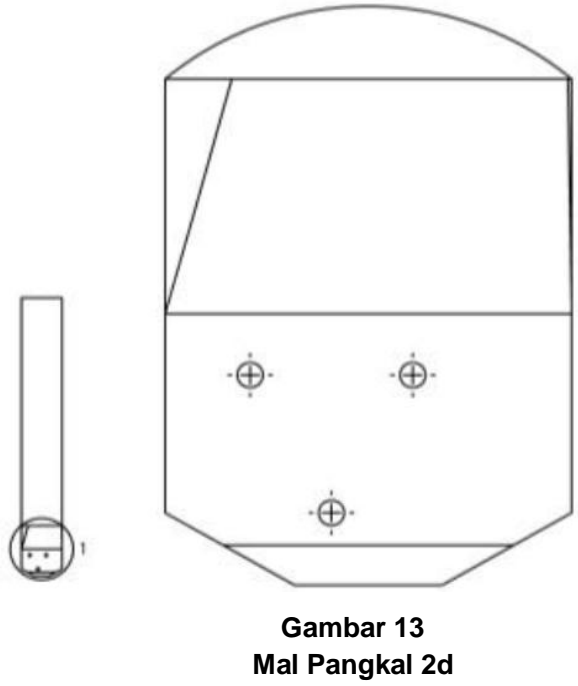

Setelah mal tertempel selanjutnya dilakukan pemotongan sisa kayu di belakang mal dan disudut melakang pangkal bilah dengan kedalaman 0,5 cm dan panjang $1 \mathrm{~cm}$. bagian ini dibuat agar bilah tidak menabrak dudukan bering pada as hub generator. Setelah pemotongan selesai selajutnya dilakukan 
drilling pada titik yang sudah ditandai pada mal. Proses drilling dilakukan dengan bor duduk agar arah pengeboran tegak lurus terhadap bidang pangkal bilah. Selanjutnya pangkal dihaluskan dan dapat dicoba dipasang di hub generator.

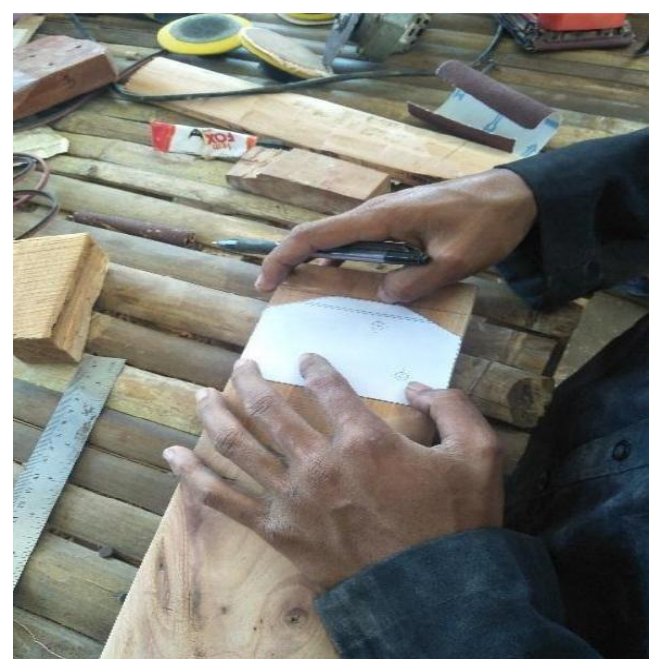

(a)

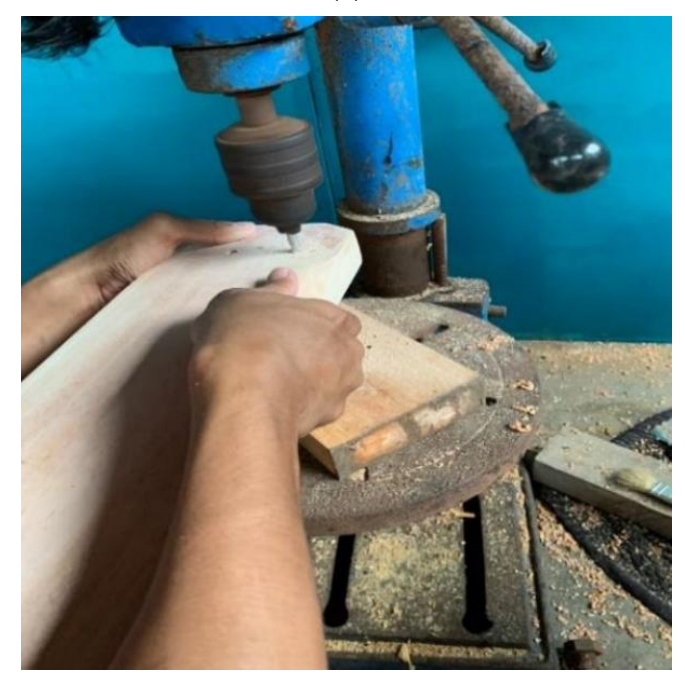

(b)

Gambar 14.

Proses Pembuatan Pangkal (a) dan Proses Pelubangan pada Pangkal (b)

\section{Pelapisan}

Proses pelapisan yaitu suatu proses melapisi bilah dengan pernis atau cat epoxy dengan tujuan agar sudu yang dibuat tidak mudah patah.

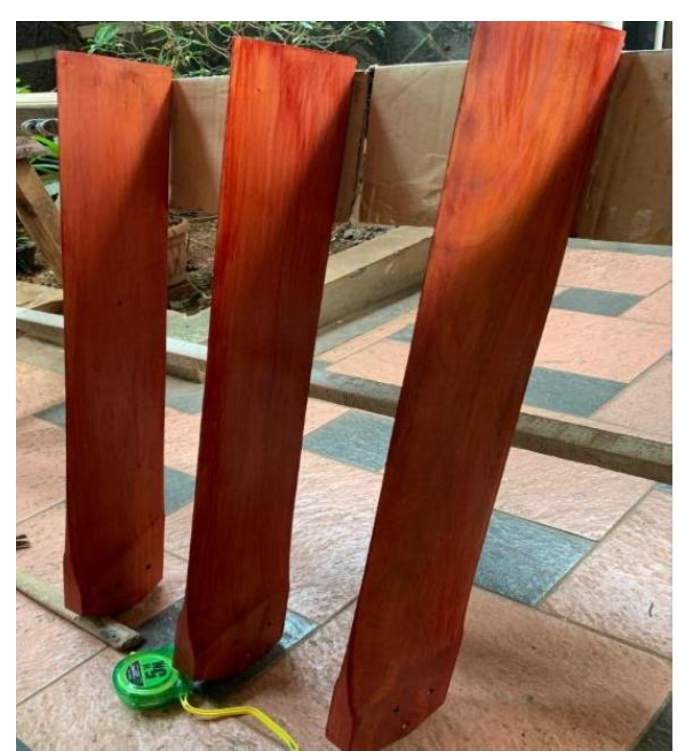

Gambar 15.

Bilah yang telah di cat

\section{KESIMPULAN}

Kesimpulan yang dapat di ambil dari proses manufaktur di atas adalah :

1. Proses manufaktur bilah Horizontal Axis Wind Turbine (HAWT) tipe Taperless dengan Airfoil S3024 terdiri dari perancangan, pemilihan material/bahan, proses manufaktur.

2. Bahan yang digunakan untuk manufaktur bilah Horizontal Axis Wind Turbine (HAWT) tipe Taperless dengan Airfoil S3024 adalah mnggunakan kayu mahoni. 
Hasil manufaktur bilah Horizontal Axis Wind Turbine (HAWT) tipe Taperless dengan Airfoil S3024 didapatkan panjang jari-jari $0.8 \mathrm{~m}$, chord linear dari 0,12 m, sudut puntir $10.27^{0}$ $5,37^{0}$.

\section{DAFTAR PUSTAKA}

[1] Indonesia Energy Outlook. 2018. Badan Pengkajian dan Penerapan Teknologi (BPPT). Jakarta

[2] Zahra, I. N. 2016, Dasar-Dasar Perancangan Bilah, Lentera Bumi Nusantara, Tasikmalaya, Jawa Barat.

[3] Tim Lentera Angin Nusantara. 2014. Pengenalan Teknologi Pemanfaatan Energi Angin. Tasikmalaya, Jawa Barat.

[4] Dahlan, B. 2016, Rancang Bangun BalingBaling Kincir Angin Menggunakan Naca 4412 Dan 4415 Dari Bahan Kayu Mahoni
(Swietenia Macrophylla) Dan Pinus (Pinus Merkusii), Tesis - Sf 092006 Program Magister Bidang Keahlian Fisika Instrumentasi Jurusan Fisika Fakultas Matematika Dan IImu Pengetahuan Alam Institut Teknologi Sepuluh Nopember, Surabaya.

[5] Madi. 2016. Studi Perancangan Horizontal Axis Wind Turbine Dengan Perbedaan Desain Air Foil Pada Bilah Jenis Tapper Untuk Pembangkit Listrik Tenaga Angin Laut Di Pantai Ciheras, Pt Lentera Angin Nusantara. Surabaya.

[6] Piggott, H., \& Blow, J. 2011. Windpower Workshop: Building Your Own Wind Turbine. Centre for Alternative Technology. 